\title{
Cross-Industry Sectoral Study: Interactions and Challenges of Requirements Engineering in the Early Phase of Product Development
}

\author{
Joshua Fahl ${ }^{1}$, Tobias Hirschter ${ }^{1}$, Hansjörg Maier ${ }^{2}$, Albert Albers ${ }^{1}$ \\ ${ }^{1} I P E K$ - Institute of Product Engineering, Karlsruhe, Germany \\ joshua.fahl@partner.kit.edu; tobias.hirschter@partner.kit.edu; albert.albers@kit.edu \\ ${ }^{2}$ Dr. Ing. h.c. F. Porsche AG, Weissach, Germany \\ hansjoerg.maier@porsche.de
}

\begin{abstract}
Product development is undergoing a profound change: Digitization, Industry 4.0 or the interconnected end-to-end product are trends that offer great innovation potential across industries, but strongly influence the development of new product generations in the product portfolio. In addition, many industry sectors - such as automotive product development - have in recent years greatly optimized common parts and platform strategies in order to achieve synergetic cost reductions. This raises the question of how conflicting requirements of customers and providers can be taken into account simultaneously in the early phase to guarantee an optimum combination between cost input and innovation potential. The aim of the cross-industry sectoral study in this paper was to gain a deeper understanding of the challenges of requirements engineering and the individual use of existing knowledge in early development phases. For this purpose, a workshop (consisting of five individual sessions with 8-16 participants each) was conducted by two independent moderators within the framework of an expert forum, the re:work Smart Requirements Engineering 2019. Building on the discussion of the workshop results, essential findings were consolidated with the participants at the end of each session and fields of action were synthesized. The survey clearly illustrated that regardless of company size or professional experience, the use of the reference system was considered a genuine success factor, which was unanimously not identified as "creativity hindering". Short iteration cycles, even in large companies, are necessary to validate the consideration and integration of customer, user and provider benefits. Furthermore, the creation of a uniform language, comprehensible structures and models is necessary. The respondents pointed out that functions are suitable as a link between properties and technical realization for evaluating the maturity level of a product specification. In addition, a consistent understanding of how to utilize the reference system can enable a structured product specification in the early phase of product development of new product generations.
\end{abstract}

Keywords: Cross-Industry Sectoral Study, Interactions, Challenges, Requirements Engineering, Early Phase of Product Development 


\section{Introduction}

Product development is undergoing a profound change: Digitization, Industry 4.0 or the interconnected end-to-end product are trends that offer providers great innovation potential across industries, but strongly influence the development of new product generations in the product portfolio. In addition, many industry sectors - such as automotive - have in recent years greatly optimized common parts and platform strategies in order to achieve synergetic cost reductions. This raises the question of how conflicting requirements of customers and providers can be taken into account simultaneously in the early phase to guarantee an optimum combination between cost input and innovation potential. For this purpose, coping with the transformation in product development, the chances and risks of a solution-open and on the other hand solution-specific product development are to be discussed with experts from various industries in a workshop. Hence, a workshop was conducted by two independent moderators within the framework of an expert forum. Together, approaches are to be developed which unite the conflicting development approaches and support the product developer in requirements engineering. The key findings are the use of a reference system as enabler for structured product specification, short iteration cycles for validation and a need for uniform language, comprehensible structures and models.

\section{Basic Principles and State of Research}

\subsection{Early Phase of Product Development}

The paradox of product development points out that in the early stages of product development one can change a great deal, but hardly knows the impact of the decisions; whereas in later stages one can judge much more accurately, but hardly change at all (Albers, A., Walch, M., \& Bursac, N., 2016). Case studies also show that decisions made in the early phase of product development have a major impact on future process and product properties such as quality, costs and development time, and thus strongly determine the success of the project (Cooper, R. G., \& Kleinschmidt, E. J., 1993). The partly used term "fuzzy front end" refers to the less structured character of the early phase (Khurana, A., \& Rosenthal, S., 1997). This is mainly due to the high level of uncertainty (McManus, H., \& Hastings, D., 2005). The uncertainty may arise due to a lack of knowledge or a lack of definition. While the knowledge gap describes a lack of acquired knowledge for the rational solution of a development task, the definition gap is understood as a lack of definitions and specifications. Consequently, the goal in product development is to continuously reduce the uncertainty by means of an iterative procedure and intelligent requirements engineering (Lindemann, U., \& Lorenz, M., 2008). According to the extended ZHO model, it is necessary to iteratively develop both the system of objectives and the system of objects as well as to explicate and document them by means of product models (Albers, A., Lüdcke, R., Bursac, N., \& Reiß, N., 2014). The Early Phase in the model of PGE - Product Generation Engineering starts with the initiation of a project and ends with the evaluation of a product specification (Albers, A., Rapp, S., Birk, C., \& Bursac, N., 2017). The product specification contains information regarding the technologies and subsystems used as well as their adoption and new development shares. It enables a valid evaluation of the product to be developed with regard to the relevant parameters such as producibility, necessary resources and technical and economic risk (Albers, A., Rapp, S., Birk, C., \& Bursac, N., 2017).

\subsubsection{Requirements Engineering}

Requirements engineering is a systematic approach to the specification and management of requirements (Pohl, K., \& Rupp, C., 2011). The objectives of the approach are: knowing the wishes and needs of all stakeholders, specifying requirements by consensus, documenting them 
in a standard-compliant manner and managing them systematically. This results in the four main activities of identifying, documenting, checking and tuning (in other words, validating) and managing elements of the system of objectives (Pohl, K., \& Rupp, C., 2011). The most important of these elements are the objectives (Ebel, B., 2015), requirements (IEEE, 1990) and boundary conditions (Albers, A., Ebel, B., \& Lohmeyer, Q., 2012). The increasing complexity of the systems to be developed is directly reflected in the increase in complexity of the associated objectives, requirements and boundary conditions (Grimm, K., 2003). These elements of the system of objectives are groundbreaking for the course of the entire product development, because only when objectives are correctly understood, the planning, execution and testing of goal-oriented activities can be performed (Albers, A., Klingler, S., \& Ebel, B., 2013). The role of requirements engineering as a success factor for companies was underlined by research results, which have established that companies with a strongly developed systematic requirements engineering can record above-average growth (Q SchmidtKretschmer, M., Gericke, K., \& Blessing, L., 2007).

\subsubsection{Product Models}

One type of models used in product development are product models. These are mainly created to explicate the current development status. Thus, they serve as a communication basis and support the analysis of the system of objects for the extension of the knowledge base (Andreasen, M. M., 1994). This facilitates an iterative procedure (Albers, A., \& Lohmeyer, Q., 2012). During product development, a large number of heterogeneous models are created, such as CAD models, finite element models, text documents such as functional and performance specifications as well as tables and parts lists (Schabacker, M., Szélig, N., \& Vajna, S., 2013). These are created for a specific purpose and managed in knowledge management systems. Due to the reduction dilemma, however, it is a great challenge to keep these heterogeneous models consistent with each other (Lohmeyer, Q., 2013). One approach to counteract this dilemma is the Model Based Systems Engineering (MSBE) (INCOSE, 2007). Here, a crossdomain model is created which can be processed by the different stakeholders. The considerations for strategic product identification by means of a product profile (Albers, A., Heimicke, J., et al., 2018) can be converted in the model of PGE into a first, developmentrelated product description and into a product model (Albers, A., Hirschter, T., Fahl, J., Woehrle, G., \& Rapp, S., 2020) with three system views (properties, functions and physical elements) over different system levels (System-of-System, Supersystems, System-of-Interest and Subsystems). The product model supports the concretization in the technical problem solving process from a rather solution-open to solution-specific description of the product generation (Albers, A., Heitger, N., Haug, F., Fahl, J., Hirschter, T., \& Bursac, N., 2018). Furthermore, specific information from a reference system (Albers, A., Rapp, S., et al., 2019) can be analyzed and abstracted.

\subsection{SPALTEN Problem Solving Methodology}

The SPALTEN problem solving methodology according to Albers is a procedure for the operative problem resolution of different boundary conditions and degrees of complexity (Albers, A., Burkardt, N., Meboldt, M., \& Saak, M., 2005). The method can be placed between the two extreme forms of actual-state and target-state oriented models of operative problem solving. SPALTEN is structured as an German acronym. Therefore, only a few segments are used. This facilitates a stringent procedure for product developers and allows them to concentrate on problem solving. Other commonly used representatives are the problem-solving cycle of systems engineering according to Daenzer \& Huber (1996) and the Munich procedure model (Lindemann, U., 2009). The SPALTEN process consists of seven steps that can be applied sequentially in the problem-solving process, whereby individual steps can be skipped. 


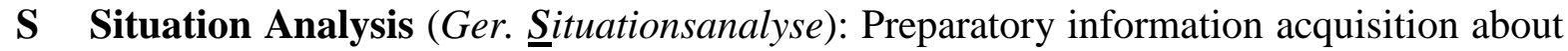
target and actual state as well as associated boundary conditions.

P Problem Containment (Ger. Problemeingrenzung): Investigation of the collected information to narrow down the core of further consideration. The aim is to determine the cause and effect of the target-actual deviation. Based on this, decision criteria are defined.

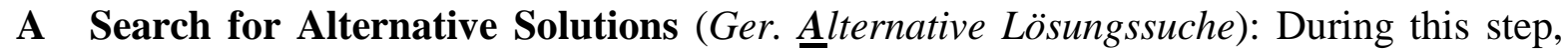
possible solutions or alternative courses of action are developed to overcome the difference between the target and actual situation.

L Selection of Solution (Ger. L Lösungsauswahl): Comparison of the identified alternatives for action and selection of a solution to be implemented according to the previously defined criteria.

T Analysis of the Level of Fulfillment (Ger. Tragweitenanalyse): Systematic investigation and weighing of opportunities and risks associated with the solution selection made. By changing perspectives, one assumes that the solution has already been implemented and tries to analyze the consequences.

E Make Decision/Implement (Ger. Entscheiden/Umsetzen): Decision to implement the solution, and implementation of the solution by those responsible.

N Recapitulate/Learn (Ger. Nachbereiten/Lernen): Reflection of the problem-solving process and, if necessary, recording of findings for future processes in the sense of a continuous improvement process (CIP).

An Information Check (IC) is performed after each step to check whether the information base is being used sufficiently and whether it is adequate to carry out the next step. The SPALTEN problem solving methodology has a fractal character. This means that each individual SPALTEN step can again be processed by a separate SPALTEN process (Albers, A., Braun, A., \& Muschik, S., 2010).

\section{Research Objective, Questions and Approach}

The research objective of the contribution is a contextual understanding of cross-industry sectoral interactions and challenges of requirements engineering and the individual application of existing knowledge in the early phase of product development. Subsequently, fields of action for future research will be synthesized from the findings and insights. The concrete implementation of a comprehensive requirements engineering and the implications for a provider have hardly been described in the literature or analyzed in practice so far (e.g. Fricker, S., Grau, R., \& Zwingli, A., 2015 or Kauppinen, M., Vartiainen, M., Kontio, J., Kujala, S., \& Sulonen, R., 2004). Thus, there is the potential to investigate a profound problem containment and search for alternative solutions with experts from practice. An explorative study is a suitable instrument for analyzing this topic (Dieckmann, A., 2008). For this purpose, a workshop - a qualitative research method - was selected as a tool for empirical investigation with experts. In workshops, problems and questions are often processed in a group or used to generate ideas. In contrast to bilateral discussions (e.g. with specialists), a workshop promotes spontaneous expression of opinion through its constructive working atmosphere (Krüger, D., 2006). An independent moderator should not be actively involved in the discussion, but rather focus on the goal-oriented moderation of the expression of opinion. Furthermore, the moderator should be encouraged to involve as many participants as possible in the discussion. In addition, the moderator can steer the dialogue if the feedback of the participants deviates from the original topic of the question (Kromrey, H., 2002). If the participants in a workshop are made up of cross-industry sectoral experts, a detailed and constructive discussion is fostered, taking into account different perspectives on the issue (Lamnek, S., 1998). 
The workshop with alternating participants was primarily designed to find answers and solutions to research questions and challenges in the context of the early phase of product development. The following, crisp research question structured the study design as well as procedure and paved the way for new, specific knowledge:

- Do references serve as a basis in the early phase of product development?

- Which coherent views of a product are considered and subsequently modelled in the early phase of product development?

- What types of elements of a product are considered in the product specification?

- What differentiation between various functional levels and their understanding is necessary?

- How does the product developer assess the maturity level of a product specification?

\section{Study Design and Procedure}

An empirical study was carried out as the basis for answering the objective within the framework of an expert forum, the re:work Smart Requirements Engineering 2019 ${ }^{1}$. The event is an industry forum at which 120 requirements and product managers and systems engineering experts from the dominant states of the German speaking D/A/CH area (Germany (D), Austria (A) and Switzerland $(\mathrm{CH})$ ) will jointly discuss how to deal with requirements and the challenges of efficient requirements engineering for mechatronic product development.

The first conference day featured numerous keynote speeches by selected experts from the industry, each of whom presented an industry-specific situation analysis and problem containment. In some cases, industry-specific solution alternatives for challenges in requirements engineering were outlined. Dr. Hansjörg Maier of the Dr. Ing. h.c. F. Porsche AG focused his presentation "Property and Function-oriented Development of Future Sports Cars" on PGE - Product Generation Engineering in the System-of-Systems and requirements definition in sports car portfolio management. He outlined the efficient way to the best overall package by structuring the early phase and the transfer to series development. As a further focal point, Dr. Maier referred to functional concepts that promote the dialogue between requirements, technology and project premises to solve ambitious conflicts of objectives with benefit for the customer. Finally, he introduced methodical approaches and practice transfer, consequently the fit/gap between theory and practice. In particular, this keynote presentation was intended to prepare participants for a moderated workshop - the core of the investigations in this contribution - on the second day. Based on the added value generated by networking collective knowledge, attendees from different industries and with different perspectives thus enter into focused and constructive discussions on focused topics. The five individual sessions of 45 minutes each are supplemented by a questionnaire, which was carried out with the participants in advance in order to record the participants' opinions. The concept for collecting the findings in the workshop is based on the Delphi method (Linstone, H. A., \& Turoff, M., 2002). In other words, the results are presented to a (new) group of experts in order to discuss what has already been learned and to be able to narrow down the problems and find alternative solutions. The problem-solving team was therefore continuously adapted to make the best use of the expertise of the participants. The discussion in the first round on the results of the situation analysis (Questions 1 to 5) can be seen as a Delphi iteration. The five questions were formulated in advance based on participatory observation of the authors in the automotive industry, expert discussions, literature research and then pre-selected by independent organizers of the forum. Consequently, the fifth group answered all questions and then discussed the results of the previous groups, whereas the first group only asked one question (cf. Figure 1).

\footnotetext{
${ }^{1}$ URL: https://www.smart-requirements-engineering.de - Date of last retrieval: January $30^{\text {th }} 2020$.
} 


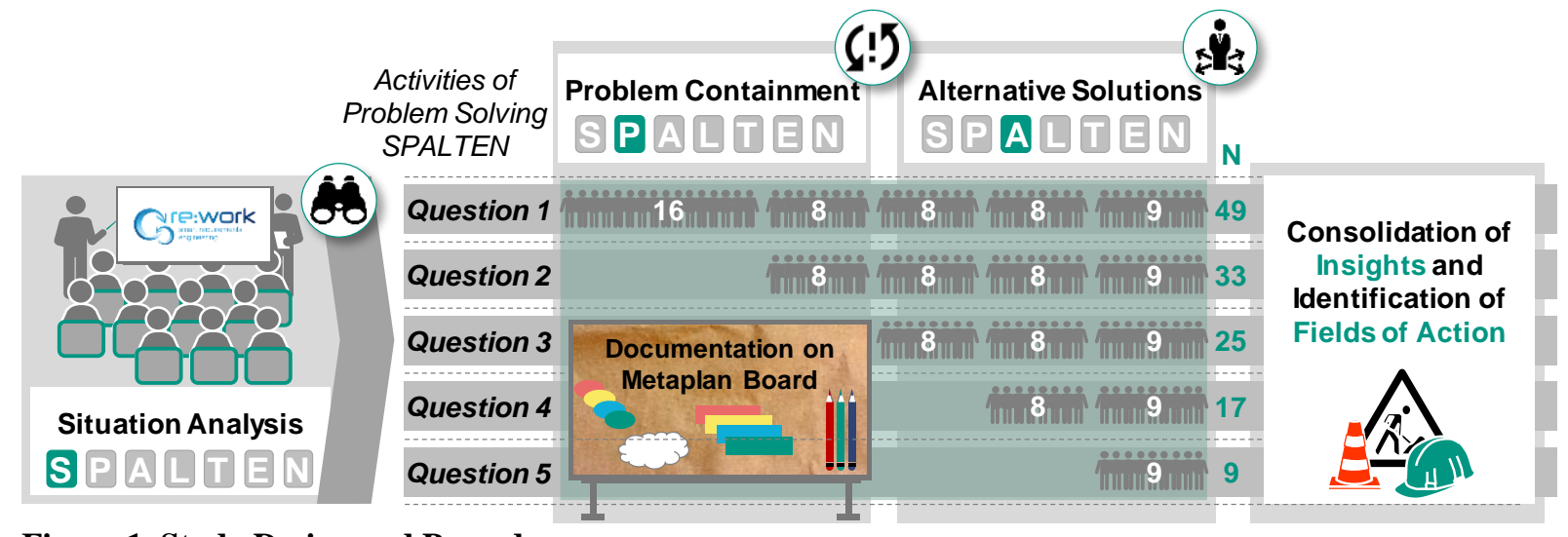

Figure 1. Study Design and Procedure.

The moderators welcomed their guests and briefly introduced the main topics, hypotheses and questions by means of a condensed situation analysis (cf. Figure 1). The group members (between 8 to 16 participants) then first answered the given questions (questionnaire) in order to be able to narrow down problems for the described situation and to find alternative solutions. At the end of each round, the findings were consolidated and fields of action for the specification were identified though an information check (IC). This was done by means of a metaplan board, which in turn was used in the following round to present the results of the preceding group. Summary findings, considerations and fields of action were recorded using discussion cards and other documentation material as well as being linked visually. Thus, each group was assigned a question, whereby the questions of the previous groups were answered in advance without knowledge of the results. The outlined procedure (cf. Figure 1) is particularly suitable when different questions build on each other, the answering of individual questions requires more time, the confrontation of different points of view improves the result and a large number of participants are to be divided up.

Altogether 49 product developers from different hierarchical levels - from (senior) manager (55.1\%) to board member/managing director $(18.37 \%)$ - participated. The following figures show the distribution of participants by industry sector or company size (cf. Figure 2) as well as by professional experience and country of origin (cf. Figure 3).
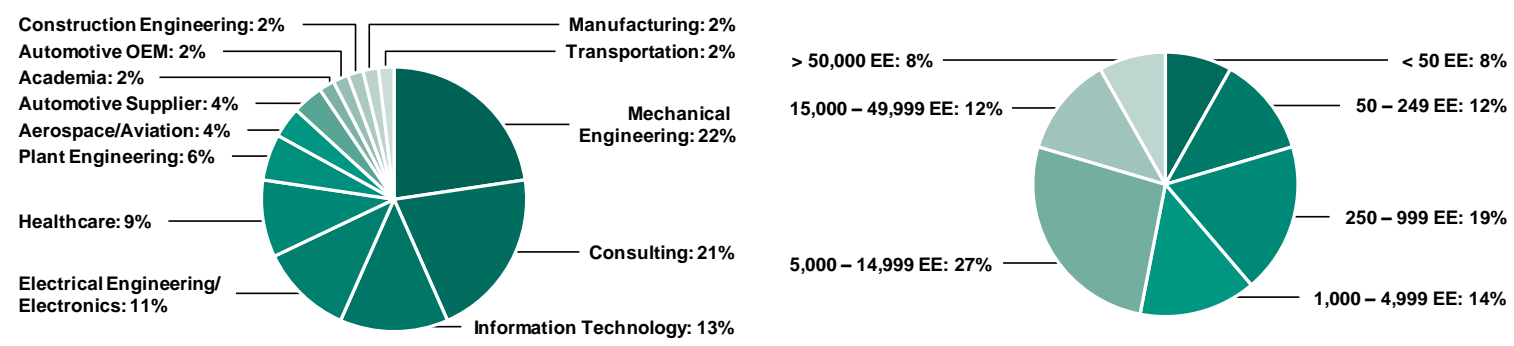

Figure 2. Distribution of Respondents by Industry Sector (left) and by Company Size in [Employees] (right).

The participants' companies are mainly active in the fields of mechanical engineering (22\%), consulting (21\%) and information technology (13\%). The heterogeneous distribution of respondents from the 13 industry sectors shows that the study can be used to determine a crossindustry sectoral opinion, with the automotive industry clearly in the minority with only one representative (2\%) (cf. Figure 2, left). Figure 2 on the right also shows that the majority of respondents (46\%) can be assigned to large companies with more than 5000 employees (EE). At the same time, small companies and start-ups $(<250 \mathrm{EE})$ are just as well represented with almost a fifth. The arithmetic mean is 16,248 EE. In addition to the arithmetic mean, the median and the truncated mean were calculated at $\alpha=5 \%$ in order to adjust for the influence of 
aberrations. Since a comparison of the values does not show any significant deviation, the data are not distorted by discordant values (Fahrmeir, L., Künstler, R., Pigeot, I., \& Tutz, G., 2010).
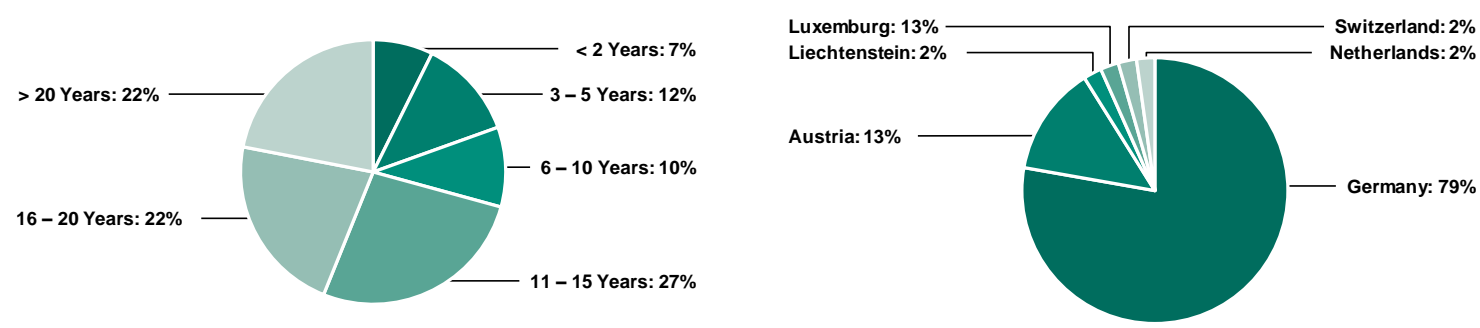

Figure 3. Distribution of Respondents by Work Experience in [Years] (left) and by Country (right).

Participants attending the workshop have an average of 14.39 years of professional experience, almost three-quarters have more than 10 years of professional experience, while only $7 \%$ are considered to be career starters ( $<2$ years). Most of the participants came from Germany or German-speaking EU countries (cf. Figure 3). Overall, it can thus be concluded that the study included a high number of senior product influencing participants from the major companies (in terms of size) in the D/A/CH countries. Drawing on the discussion of the workshop results key findings were consolidated with the participants at the end of each session and fields of action were synthesized (cf. Section 5).

\section{Findings of Problem Containment and Search for Alternative Solutions regarding the Interactions and Challenges of Requirements Engineering in the Early Phase of Product Development}

This chapter presents the individual questions and the evaluation of the questionnaire as well as the results of the problem containment, alternative solutions and derived fields of action.

\subsection{Utilization of the Reference System in the Early Phase of Product Development}

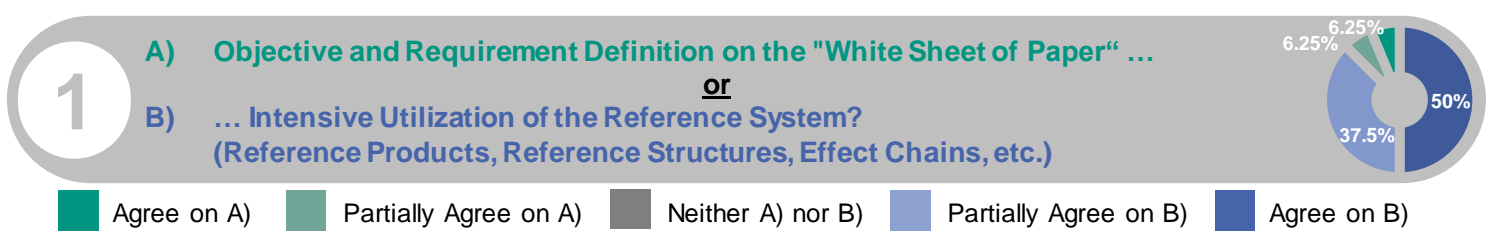

Figure 4. First Question - Utilization of the Reference System in the Early Phase of Product Development.

The first question (cf. Figure 4) aims to inquire the basic procedure in the early phase of the product developers' activities. The opposing statements A and B form the starting point of the subsequent discussion. In the evaluation, it becomes noticeable that $87.5 \%$ of the participants at least partially agree with the use of the reference system and only $6.25 \%$ clearly prefer the "white sheet of paper" approach. In the ensuing discussion on problem containment (cf. Figure 5 , left), however, it was jointly established that even ideas originating on a "white sheet of paper" could be traced back to "reference products that support the creative product developer in mental generation of ideas". The groups were unanimous in their opinion on how to deal with the reference system, so that it must be seen as the "core task of the product developer" in order to "deal efficiently and effectively with his development task, to create and to find solutions". Based on their experience, the workshop participants found that reference products are particularly suitable for describing the customer, user and provider benefits in relative terms and that the technical and financial feasibility can be assessed at an early stage. Furthermore, the respondents jointly stated that in order to use reference products, their origin and information validity must be known to ensure transparency in the specification process. 


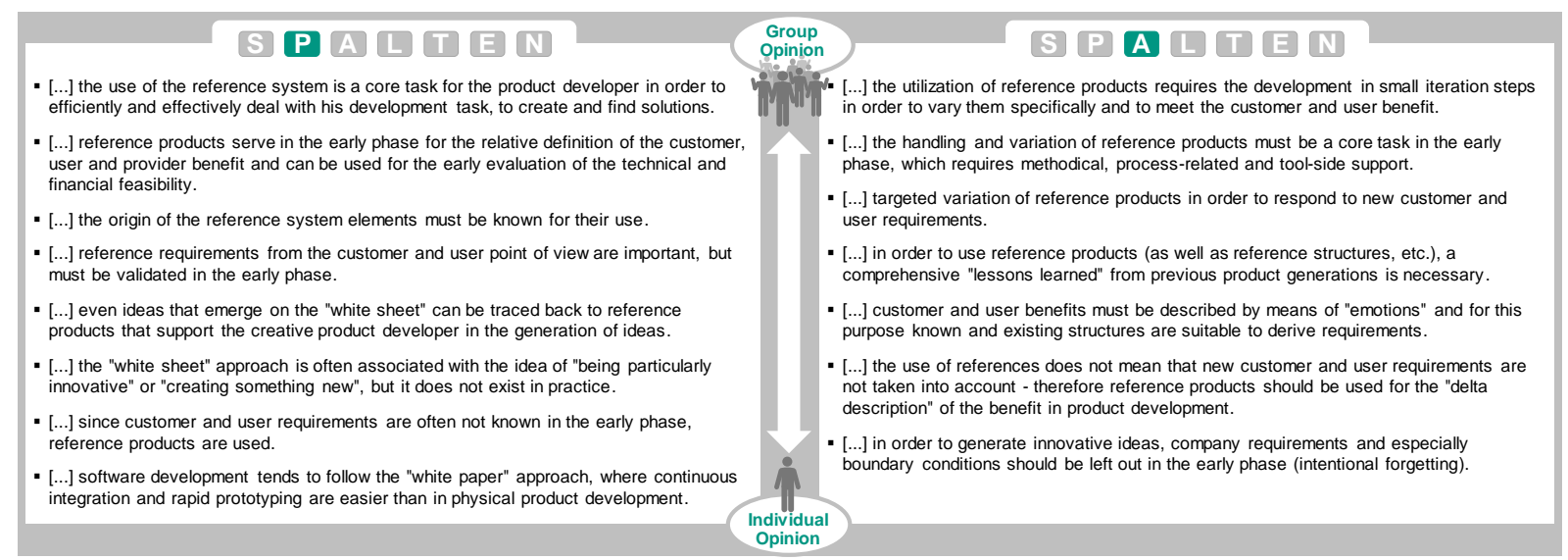

Figure 5. First Question - Study Results from Problem Containment and Search for Alternative Solutions.

Thereafter, the group participants developed alternative solutions (cf. Figure 5, right). It is noteworthy that regardless of the size of the company, the participants considered "development in small iteration steps" to be a success factor in order to be able to vary the reference products according to customer and user benefit. The core task of "handling and varying" reference products must be supported methodically, process-wise and tool-sided. In addition, the respondents emphasized that a description of "emotions" to consider customer and user benefits increases the innovation potential and that "known and existing structures to derive requirements" are particularly suitable for this purpose. Based on the results, the respondents identified four promising fields of action, whereby in the discussion, the use of the reference system was not finally assessed as "hindering creativity", but rather as "promoting creativity", "focusing" and "increasing efficiency".

\section{Conclusion expressed in terms of identified fields of action from the first question}

I. Strengthening dealing with the reference system as a core task

II. Use of reference products in the product specification

III. Planning the product specification using short iteration loops

IV. "Delta description" of a product generation using reference products

\subsection{Coherences and Modelling of the Views on a Product in the Early Phase of Product Development}

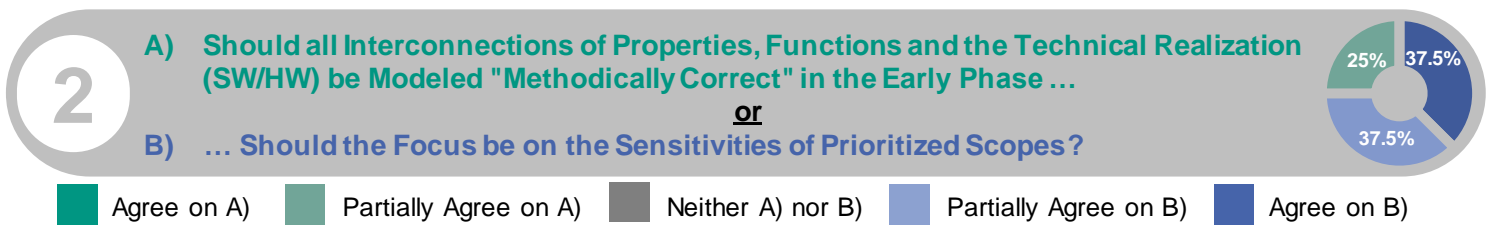

Figure 6. Second Question - Coherences and Modelling of the Views on a Product in the Early Phase of Product Development.

The second question is intended to gather the respondents' assessment of the modelling of properties, functions and their technical realization in the early phase (cf. Figure 6). In this context, $75 \%$ of the product developers agreed at least partially with a targeted prioritization, since a "methodologically correct", comprehensive modeling is very time-consuming and the capacity for this is not available, especially in the early phase. The respondents unanimously stated that prioritization in the early phase is based on the subjective opinion of individuals and that there is little or no methodological support for this process (cf. Figure 7, left). The decisions made are not or only insufficiently validated afterwards. In order to avoid having to model the interactions again in each product generation, the "use of reference structures" is helpful however, these are usually not adequately documented in previous product generations. 


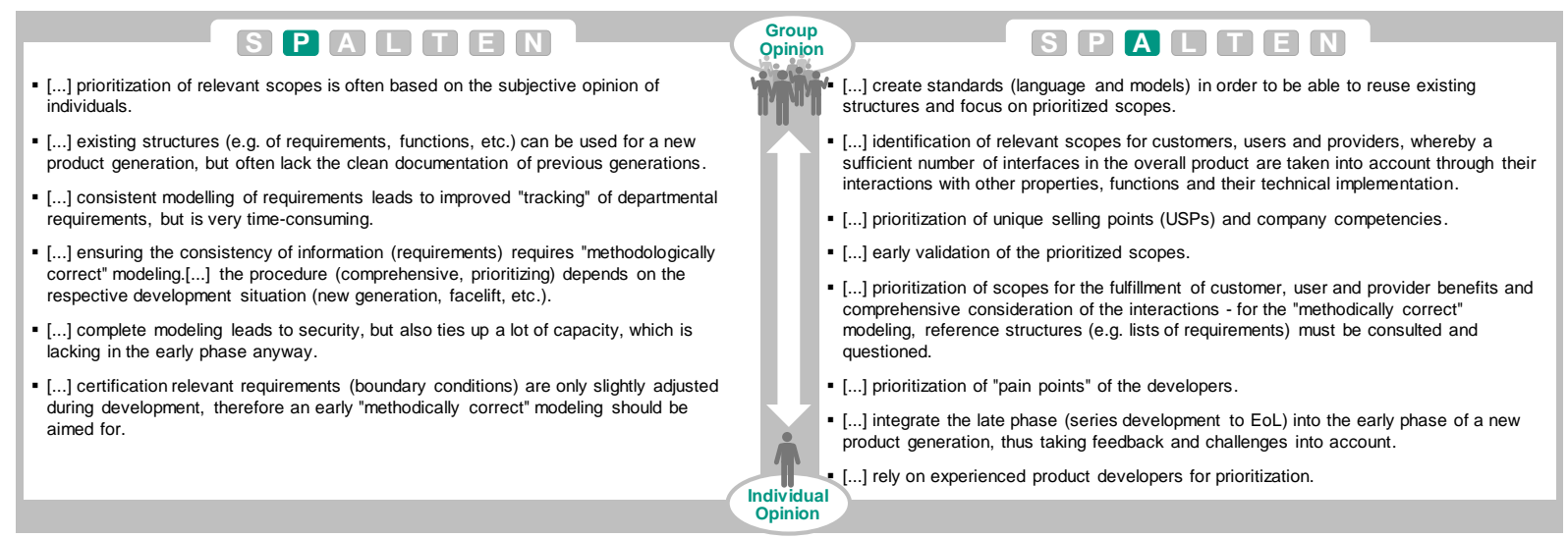

Figure 7. Second Question - Study Results from Problem Containment and Search for Alternative Solution.

A "methodologically correct" modelling is particularly important for certification-relevant scopes, where it can be observed that these " perimeters are only slightly adapted in the development process". The respondents further stated as a proposed solution that prioritization from the customer, user and provider perspective results in a sufficiently large number of properties, functions and their technical realization, and that non-prioritized scopes are also considered when considering their interactions (cf. Figure 7, right). However, this requires the early and continuous validation of the prioritized dimensions. In prioritization, unique selling points and company competencies must be taken into account, and experienced product developers should be involved. Prioritization, as the task of the product developer, was highlighted as a field of action, whereby the creation of standards (structures, language, models, interfaces, etc.) is necessary to support modeling in the early phase. In addition, a uniform understanding of the system through system-/abstraction-level as a field of action is necessary.

Conclusion expressed in terms of identified fields of action from the second question

V. Prioritization of properties, functions and their technical implementation

VI. Creation of standards (structures, language, models, interfaces, etc.)

VII. Creation of uniform system / abstraction levels

\subsection{Consideration of Solution-Open and Solution-Specific Elements in the Product Specification}

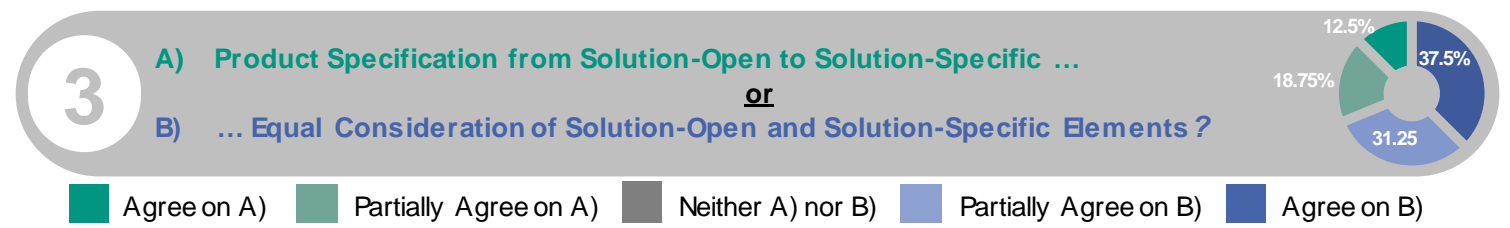

Figure 8. Third Question - Consideration of Solution-Open and Solution-Specific Elements in the Product Specification.

With the third question, the fundamental consideration of solution-open and solution-specific elements in the specification is examined (cf. Figure 8). $68.75 \%$ of the respondents stated at least partially that both solution-open and solution-specific elements must be taken into account, since solution-specific elements are already known in the early phase of product development, e.g. due to direct customer requirements or company specifications (acquisition strategies) (cf. Figure 9, left). Especially in the case of solution proposals specified by the customer, it is usually difficult to understand the actual requirements ("hidden requirements"). Furthermore, the respondents stated that it is difficult for the product developer to specify purely solution-open requirements. Rather, the interplay of solution-open and solution-specific specifications is promising. The fact that regulations often require "thinking in solutions" in 
order to be able to plan certification and release by third parties at an early stage speaks in favor of taking solution-specific elements into account.

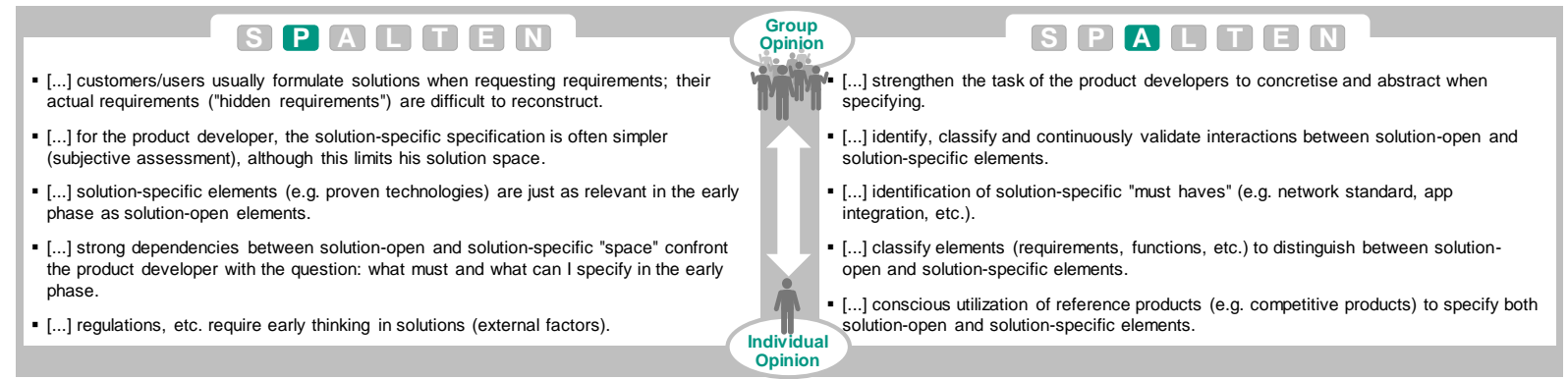

Figure 9. Third Question - Study Results from Problem Containment and Search for Alternative Solution.

As alternative solutions, the respondents stated that the task of concretizing and abstracting must be significantly strengthened in order to be able to consider both solution-open and solution-specific elements (cf. Figure 9, right). For this purpose, the interactions of the elements must be identified, classified and continuously validated. In addition, some respondents stated that the identification of solution-specific "must haves" (such as network standard) should take place at the beginning of the product specification in order to be able to further develop (e.g. application scenarios) based on its solution-specific elements.

\section{Conclusion expressed in terms of identified fields of action from the third question}

VIII. Modelling the interactions of solution-open and solution-specific elements

IX. Strengthen concretization and abstraction as core tasks of the specification

\subsection{Distinction between Different Levels of Functions}

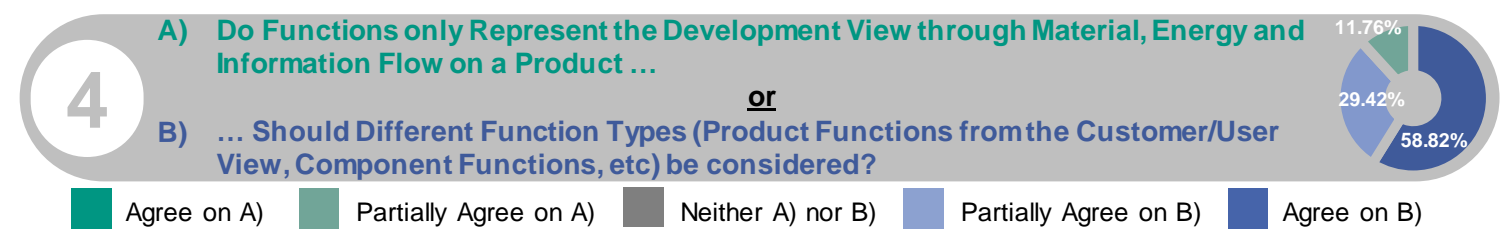

Figure 10. Fourth Question - Distinction between Different Levels of Functions.

The necessity for the differentiation of different levels of function was elaborated by the participants by means of the fourth question, in order to connect, for example, the customer and user view (input/output as event/result) and the product developer view (input/output as flow of material, energy and information) on a product. Thus, a majority of $88.24 \%$ voted at least partially in favor of differentiating between functional levels (cf. Figure 10). It should be emphasized that while respondents confirmed the need for differentiation, they also indicated that this is not done sufficiently in their organizations. Often the component perspective is adopted in function development, but the methodologically correct interconnection across different levels is not achieved. The respondents stated that this is a non-trivial task in the development process, but that the training of product developers focuses on the component perspective rather than the overall product perspective (cf. Figure 11, left). 


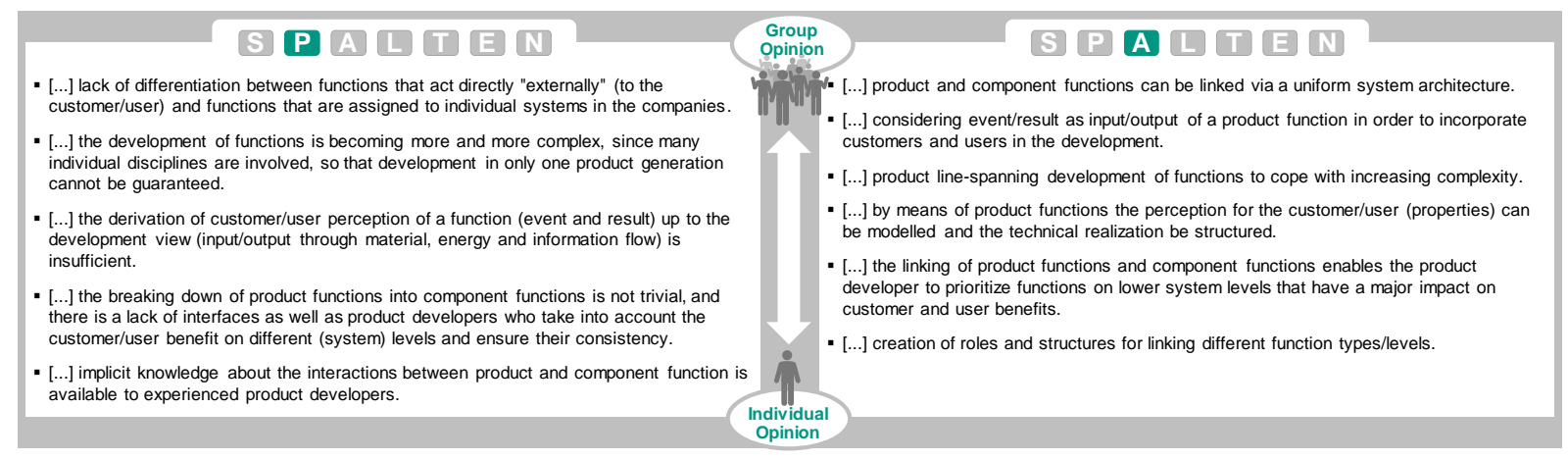

Figure 11. Fourth Question - Study Results from Problem Containment and Search for Alternative Solution.

For this reason, as well as the increasing complexity, the conclusion was drawn that a product line-spanning development of functions is necessary, as far as this is feasible in a company with a high number of different product lines and product generations (cf. Figure 11, right). The respondents stated that different levels of functions could be used to combine both the physical view of a product (software and hardware components) and the perception of customers/users (perceived properties). Functions must be taken into account in the product specification. The respondents agreed that a uniform system architecture in companies simplifies the linking of different functions. This led to the following three fields of action.

\section{Conclusion expressed in terms of identified fields of action from the fourth question}

X. Distinction between different levels of functions

XI. Strengthen customer and user perspective during function development

XII. Product line-spanning function development

\subsection{Systematic Evaluation of the Level of Maturity of a Product Specification}

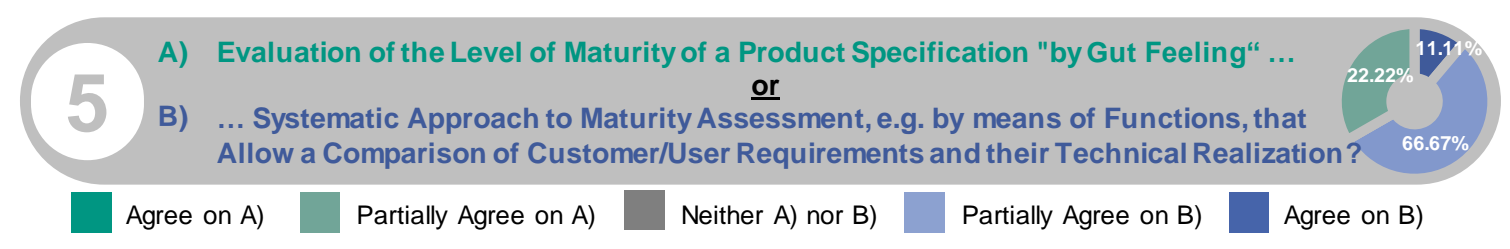

Figure 12. Fifth Question - Systematic Evaluation of the Level of Maturity of a Product Specification.

When asked the fifth question, respondents said that they considered a systematic assessment of the maturity level of the product specification to be more useful (cf. Figure 12), although the subjective assessment of experienced product developers should also be included here $(22.22 \%)$. The respondents stated that the current documentation of product specifications ( $i$. e. requirement specifications) is too confusing. The content of these documents is only known in isolated cases and therefore difficult to access for the evaluation (cf. Figure 13, left). However, functions have been proven a suitable measure to evaluate a product specification, as they combine solution-open and solution-specific elements.

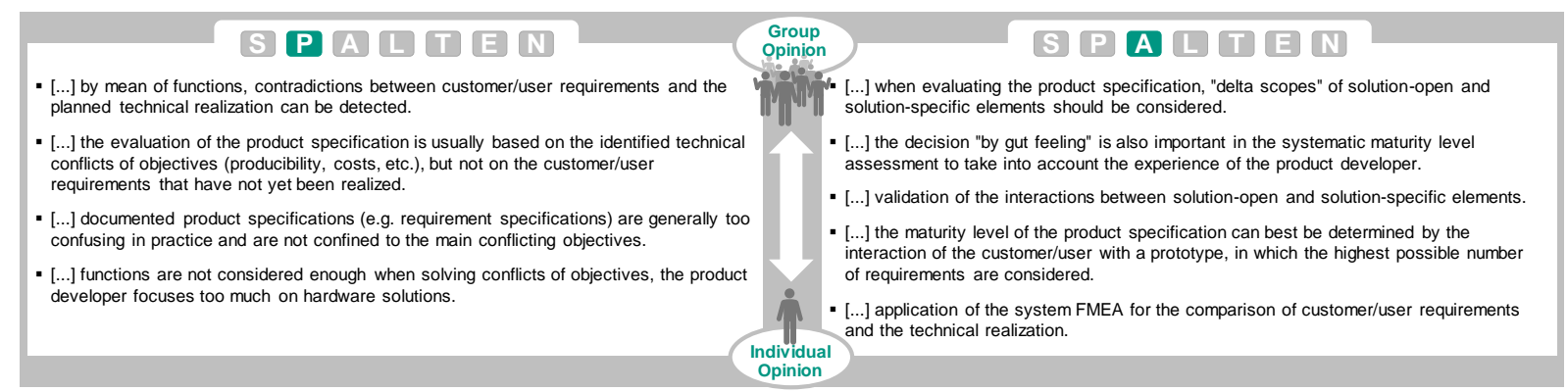

Figure 13. Fifth Question - Study Results from Problem Containment and Search for Alternative Solution. 
The integration of the customer/user for the evaluation of prototypes is considered promising by the respondents, although this is particularly challenging in large, highly competitive companies such as the automotive industry (cf. Figure 13, right). The respondents highlight the "evaluation of the product specification by solution-open and solution-specific elements" and "strengthening the modelling of functional chains of effect" as fields of action.

\section{Conclusion expressed in terms of identified fields of action from the fifth question}

XIII. Evaluation of the product specification based on the interaction of solution-open and solution-specific elements

XIV. Strengthening the modelling of functional chains of effects as a core task

\section{Summary of Insights and Identified Fields of Action}

The objective of the cross-industry sectoral study in this paper was to gain a contextual understanding of the challenges of requirements engineering amid the transformation through Digitization, Industry 4.0 or the interconnected end-to-end product and grasp the individual use of existing knowledge in early development phases. To this end, a workshop (consisting of five individual sessions with 8 to 16 participants each) was conducted by two independent moderators within the framework of an expert forum, the re:work Smart Requirements Engineering 2019. Five questions were used as a starting point for a thematic discussion with the aim of sharing, questioning and making visible common experiences, challenges and individual solution approaches. In this way, new perspectives, ways of thinking and options for action can be sustainably demonstrated for each individual.

Reflecting on research objective and questions (cf. Section 3), the survey showed that, irrespective of the size of the company or professional experience, the use of the reference system was evaluated as a success factor, which was unanimously not identified as "creativity hindering". Short iteration cycles are necessary even in large companies in order to validate the consideration of customer, user and provider benefits. In order to reduce complexity in the early phase, the respondents agreed on the prioritization of "relevant" aspects. This consideration of customer, user and provider benefits is necessary, as is the creation of a uniform language, comprehensible structures and models. In conclusion, the respondents pointed out that functions are suitable as a link between properties and technical realization when evaluating the maturity level of a product specification. Considering this background, a structuring product model with uniform system levels and views as well as a consistent understanding and differentiation of (product) properties and (product) functions is necessary. In addition, a consistent understanding of how to use the reference system, including the types of variation of properties, functions and physical subsystems for the description of new development and carryover shares of new product generations, can enable a structured product specification in the early phase of product development.

\section{Outlook}

In future research projects, the generated solutions for the fourteen identified fields of action must be selected for implementation (L) and detailed. Subsequently, an analysis of Level of Fulfillment $(\mathrm{T})$ of the selected solutions must be carried out in order to prepare the Decision/Implementation (E). The findings from Recapitulation/Learning (N) should be used to develop a reference process for product specification based on product properties in the early phase of product development. Furthermore, it is necessary to structure the specification of functional (product) concepts across product portfolios as well as supporting methods. 


\section{Citations and References}

Albers, A., Braun, A., \& Muschik, S. (2010). Uniqueness and the Multiple Fractal Character of Product Engineering Processes. In Modelling and Management of Engineering Processes. London: Springer.

Albers, A., Burkardt, N., Meboldt, M., \& Saak, M. (2005). SPALTEN Problem Solving in the Product Development. In $15^{\text {th }}$ International Conference on Engineering Design (ICED).

Albers, A., Ebel, B., \& Lohmeyer, Q. (2012). Systems of Objectives in Complex Product Development. In $9^{\text {th }}$ International Symposium on Tools and Methods of Competitive Engineering (TMCE).

Albers, A., Heimicke, J., Walter, B., Basedow, N. G., Reiß, N., Heitger, N., Ott, S., \& Bursac, N. (2018). Product Profiles: Modelling customer benefits as a foundation to bring inventions to innovations. In Proceedings of CIRP Design 2018, Vol. 70.

Albers, A., Heitger, N., Haug, F., Fahl, J., Hirschter, T., \& Bursac, N. (2018). Supporting Potential Innovation in the Early Phase of PGE - Product Generation Engineering: Structuring the Development of the Initial System of Objectives. In R\&D Management Conference 2018: R\&Designing Innovation.

Albers, A., Hirschter, T., Fahl, J., Woehrle, G., \& Rapp, S. (2020). Reference Product Model for Structuring the Specification of Complex Products by the Example of the Automotive Industry. In $13^{\text {th }}$ International Symposium on Tools and Methods of Competitive Engineering (TMCE).

Albers, A., Klingler, S., \& Ebel, B. (2013). Modeling Systems of Objectives in Engineering Design Practice. In Proceedings of the $19^{\text {th }}$ International Conference on Engineering Design (ICED).

Albers, A., \& Lohmeyer, Q. (2012). Advanced systems engineering - towards a model-based and human-centered methodology“. In $9^{\text {th }}$ International Symposium on Tools and Methods of Competitive Engineering (TMCE).

Albers, A., Lüdcke, R., Bursac, N., \& Reiß, N. (2014). Connecting Knowledge-ManagementSystems to Improve a continuous flow of Knowledge in Engineering Design Processes. In $10^{\text {th }}$ International Symposium on Tools and Methods of Competitive Engineering (TMCE).

Albers, A.; Rapp, S.; Birk, C., \& Bursac, N. (2017). Die Frühe Phase der PGE Produktgenerationsentwicklung. Stuttgarter Symposium für Produktentwicklung.

Albers, A., Rapp, S., Spadinger, M., Richter, T., Birk, C., Marthaler, M., Heimicke, J., Kurtz, V., \& Wessels, H. (2019). The Reference System in the Model of PGE: Proposing a Generalized Description of Reference Products and their Interrelations. In International Conference on Engineering Design (ICED).

Albers, A., Walch, M., \& Bursac, N. (2016). Entscheidungsunterstützung durch die Variationsanteile der Produktgenerationsentwicklung. In Konstruktion - Zeitschrift für Produktentwicklung und Ingenieur-Werktstoffe 1.

Andreasen, M. M. (1994). Modelling - the language of the designer". In Journal of Engeering Design 5.2, pp. 103-115.

Cooper, R. G., \& Kleinschmidt, E. J. (1993). Screening new products for potential winners. In Lon Range Planning 26.6, pp. 74-81.

Daenzer, W. F., \& Huber, F. (1996). Systems Engineering. Orell Füssli Verlag.

Dieckmann, A. (2008). Empirische Sozialforschung: Grundlagen, Methoden, Anwendungen. Reinbek: Rowohlt Verlag GmbH.

Ebel, B. (2015). Modellierung von Zielsystemen in der interdisziplinären Produktentstehung. Dissertation, Forschungsberichte des IPEK, Karlsruher Institut für Technologie (KIT).

Fahrmeir, L., Künstler, R., Pigeot, I., \& Tutz, G. (2013). Statistik: Der Weg zur Datenanalyse. Berlin: Springer. 
Fricker, S., Grau, R., \& Zwingli, A. (2015). Requirements Engineering: Best Practices. In Requirements Engineering for Digital Health, pp.25-46.

Grimm, K. (2003). Software Technology in an Automotive Company - Major Challenges. In Proceedings of the $25^{\text {th }}$ International Conference on Software Engineering (ICSE).

IEEE (1990). IEEE Standard Glossary of Software Engineering Terminology. The Institute of Electrical and Electronics Engineers.

INCOSE (2007). Technical Operations. Systems Engineering Vision 2020.

Kauppinen, M., Vartiainen, M., Kontio, J., Kujala, S., \& Sulonen, R. (2004). Implementing requirements engineering processes throughout organizations: success factors and challenges. In Information and Software Technology 46 (2004), pp. 937-953.

Khurana, A., \& Rosenthal, S. (1997). Integrating the Fuzzy Front End of New Product Development. In Sloan Management Review 6, pp. 103-120.

Kromrey, H. (2002). Empirische Sozialforschung: Modelle und Methoden der standardisierten Datenerhebung und Datenauswertung. Opladen: Leske + Budrich.

Krüger, D. (2006). Veränderungsprozess in der Arbeits- und Personalpolitik vor dem Hintergrund der demographischen Entwicklung: Handlungsansätze für die betriebliche Praxis. Kassel: Kassel University Press.

Lamnek, S. (1998). Gruppendiskussion: Theorie und Praxis. Einheim: Psychologie Verlags Union.

Lindemann, U. (2009). Methodische Entwicklung technischer Produkte. Berlin: Springer.

Lindemann, U., \& Lorenz, M. (2008). Uncertainty Handling in Integrated Product Development. In Proceedings of the $10^{\text {th }}$ International Design Conference, pp. 175-182.

Linstone, H. A., \& Turoff, M., (2002). The Delphi MethodTechniques and Applications. Reading, Massachusetts: Addison-Wesley.

Lohmeyer, Q. (2013). Menschzentrierte Modellierung von Produktentstehungssystemen unter besonderer Berücksichtigung der Synthese und Analyse dynamischer Zielsysteme. Dissertation, Forschungsberichte des IPEK, Karlsruher Institut für Technologie (KIT).

McManus, H., \& Hastings, D. (2005). A Framework for Understanding Uncertainty and its Mitigation and Exploitation in Complex Systems. In Engineering systems Symposium.

Pohl, K.; \& Rupp, C. (2011). Basiswissen Requirements Engineering. Heidelberg: dpunkt.

Schabacker, M., Szélig, N., \& Vajna, S. (2013). The Calculation of the Degree of Parallelization of Documents and Risk Estimation in Product Development Processes. In International Design Engineering Technical Conferences and Computers and Information in Engineering Conference (ASME).

Schmidt-Kretschmer, M., Gericke, K., \& Blessing, L. (2007). Managing Requirements or Be Managed by Requirements - Results of an Empirical Study. International Conference on Engineering Design (ICED). 